\title{
A Study and Practice of Mechanical Drawing Course Teaching Based on Wechat Public Platform
}

\author{
Xiaochang Cao* \\ College of Mechanical Engineering \\ Dongguan University of Technology \\ Dongguan, China \\ caoxc@dgut.edu.cn \\ Jianjun Jing \\ College of Mechanical Engineering \\ Dongguan University of Technology \\ Dongguan, China
}

\author{
Jianwen Guo \\ College of Mechanical Engineering \\ Dongguan University of Technology \\ Dongguan, China
}

\author{
Zhibin Zeng \\ Dongguan Hengli Mould Technology Development Limited \\ Company \\ Dongguan, China
}

\begin{abstract}
Wechat-teaching hybrid teaching is carried out for mechanical drawing course teaching based on mobile learning of Wechat public platform. Pushing practices of course information, course task and problem set solving are implemented through mobile course activity design and evaluation. According to students' feedback, it's indicated that mobile hybrid teaching based on Wechat public platform contributes to improving students' learning initiatives, imparting and consolidation of mechanical drawing knowledge and students' extension of mechanical specialty-related knowledge.
\end{abstract}

Keywords-Wechat Public Platform; Mechanical Drawing; Teaching Reform

\section{INTRODUCTION}

With rapid development of internet technology especially extensive popularization of mobile internet platform, people have gotten used to checking information, sharing their feelings and learning knowledge from smart phones. Mobile learning function, knowledge frame structure combing, afterclass review and consolidation and expansion of knowledge application are orientations of mobile learning. Wechat public platform has provided mobile, shareable and pragmatic resources for educators and learners and it can conveniently realize learning, exploration and improvement according to individualized demands. [1,2]

\section{FUNCTION OVERVIEW OF WECHAT PUBLIC PLATFORM}

Under the demand for mobile learning, Wechat has provided a new platform and application innovation space as software concentrated on mobile terminal functions. In way of "mobile internet + classroom teaching", functions provided by Wechat kits are used to carry out teaching and aided teaching, implement playback of knowledge points, assignment issuing, question answering and tutoring and realize teacher-student interaction and communication. In the meantime, customized menus can be set in Wechat public account so that the students can select pragmatic contents pushed before. On this basis, students' learning interests will be attracted. This hybrid teaching helps to dig students' consciousness of innovation and impart and consolidate knowledge, so it has more effective imparting effect than traditional classroom teaching.

\section{A STUDY AND PRACTICE OF MECHANICAL DRAWING COURSE TEACHING BASED ON WECHAT PUBLIC PLATFORM}

Mechanical drawing course, an important key required course for mechanical specialties, mainly cultivates students' map reading and drawing abilities and it's also involved in national standards for mechanical drawing. Traditional teaching of this course centers on training aids and multimedia explaining in the classroom with a lack of before-class and after-class interaction, so newly learned knowledge can't be previewed well and previously learned knowledge can't be consolidated well. Students reflect a little upon their assignments. Mutual plagiarizing phenomenon also exists due to absence of proper reference and explaining. In the meantime, this course serves a link between past and future and it has certain requirements for extension of professional knowledge. Powerful information interaction function of Wechat public account can exert educational resource sharing effect in mechanical drawing course teaching. [3]

Based on establishment of a Wechat platform for mechanical drawing course, this paper mainly guides students to take full advantages of extracurricular time to preview and consolidate knowledge points in the classroom teaching. The Wechat platform for mechanical drawing course is shown as in Fig.1. It is an effective path to realize shareability of mechanical drawing course and individualized learning. Mechanical drawing hybrid learning pattern is established respectively from four main links: knowledge introduction, course explaining and interaction and after-class knowledge extension. This paper aims at mobilizing students' initiatives in learning mechanical drawing. Through the practice of internet mobile teaching technology and extended classroom learning, mechanical drawing learning is combined with students' living practice to satisfy individualized learning demands. 


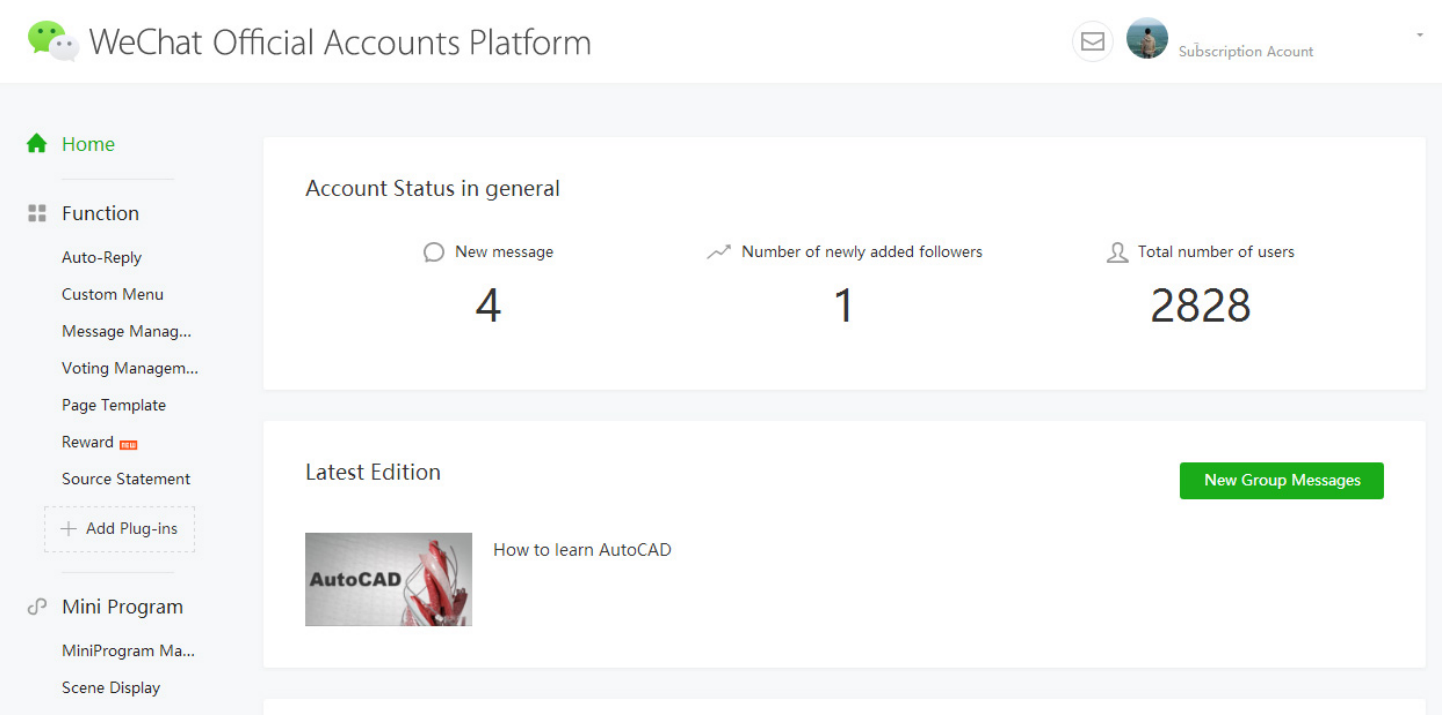

Fig. 1. The Wechat platform for mechanical drawing course

\section{A. Knowledge introduction and pushing of accumulated resources}

The teacher can push teaching resources like teaching contents and consolidating exercises to classmates from different classes through the Wechat public account. Some public teaching resources like extension of mechanical specialty-related knowledge can be pushed all everyone and these resources can be saved in the public platform so that students can view at any time.

Knowledge introduction is as such, the teacher pushes learning objectives and knowledge link to students, explain key and difficult knowledge and import related knowledge points through the Wechat public platform before the initial link of mechanical drawing teaching. The teacher uses individual Wechat platform to realize before-class guidance and discussion among students. In consideration of students' difference in mastering abilities, the user management function of the Wechat public platform is used to carry out project guidance in groups. The teacher will participate in the groups and guide students to complete before-class discussion.

\section{B. Strengthen interaction and pay attention to after-class consolidation}

Learning on the Wechat platform stresses on students' dominant roles with flexible learning time. The student's operation interface of the platform is shown as in Fig.2. Students can separately raise questions to the teacher or ask questions in the group and then solve their doubts through collaborative discussion among group members. The teacher uses message pushing function of Wechat public platform to push exercise explanation to all students. For the questions proposed by students, the teacher can conveniently give a mobile reply. If there are many students asking questions, the teacher can give centralized replies in front of the computer. Avoid combining SI and CGS units, such; as current in amperes and magnetic field in oersteds. This often leads to confusion because equations do not balance dimensionally. If you must use mixed units, clearly state the units for each quantity that you use in an equation. [4]

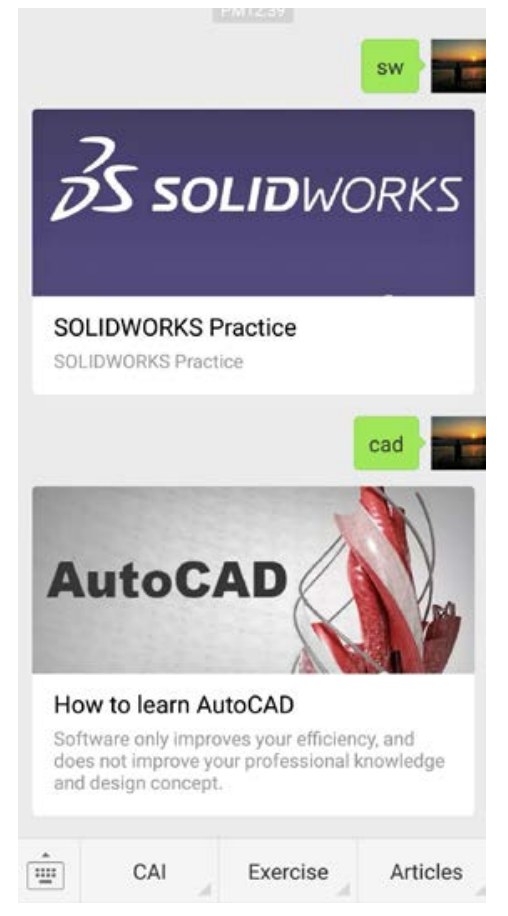

Fig. 2. The student's operation interface of the platform

In addition, the Wechat platform can also realize online question answering function. Students ask questions in the group, the teacher or other students in the group give replies and explanation and discuss together, which breaks spatialtemporal limitations. For the then off-line students, they can solve similar problems by viewing questions and replies before on the Wechat platform. The interaction statistics of teachers and students in the last year is shown as in Fig.3. 


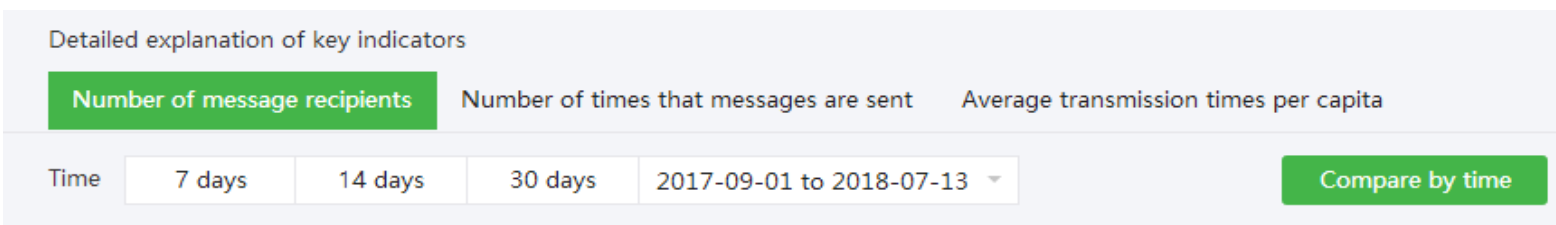

ITrend Chart

75

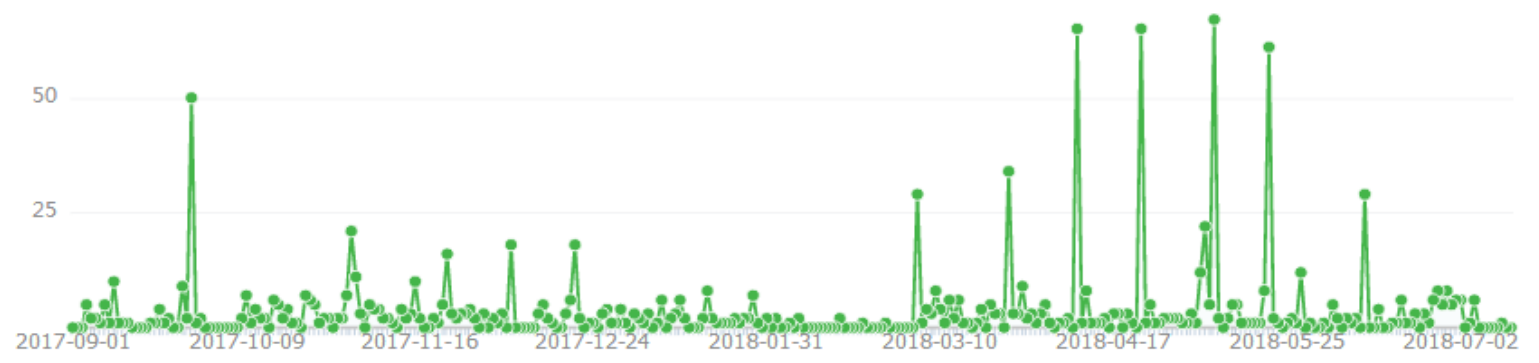

Number of message recipients

Fig. 3. The interaction statistics of teachers and students in the last year

The teacher can collect and organize questions on the Wechat platform and give centralized explanation to common or typical problems in the classroom. In the meantime, the teacher will evaluate students' participation on the Wechat platform and mobilize their initiatives and degree of participation.

\section{Knowledge extension and broadening of students' horizon}

After-class utilization of mechanical knowledge and extended utilization of after-class mechanical knowledge will help students to extend students' cope of knowledge and have a profound understanding of application of mechanical working principles in life. The statistical data of students' autonomous learning is shown as in Fig. 4. With the help of Wechat platform, the teacher can guide students to complete after-class extension. The teacher arranges students' selflearning tasks according to main project contents and asks them to release logs related to the knowledge they learn in
Wechat Circle of Friends. Log forms can be picture, video, audio, etc., and contents can be self-created or forwarded from others. This can stimulate students to take initiatives to establish mechanical knowledge and actively utilize the learned mechanical principles. In this way, students' scope of knowledge can be broadened and the learned knowledge can be consolidated.

Through statistical analysis information like user analysis and image-text message analysis on Wechat public platform, the teacher can intuitively know about information like reading quantity and forwarding quantity of various material sources within the platform. In random interviews, students express that learning course project objectives and contents through the Wechat public platform can make it possible for them to get sufficient understanding and preparation of the course, which can lay a good foundation for discussion among classmates in the classroom and smoother communication with the teacher.

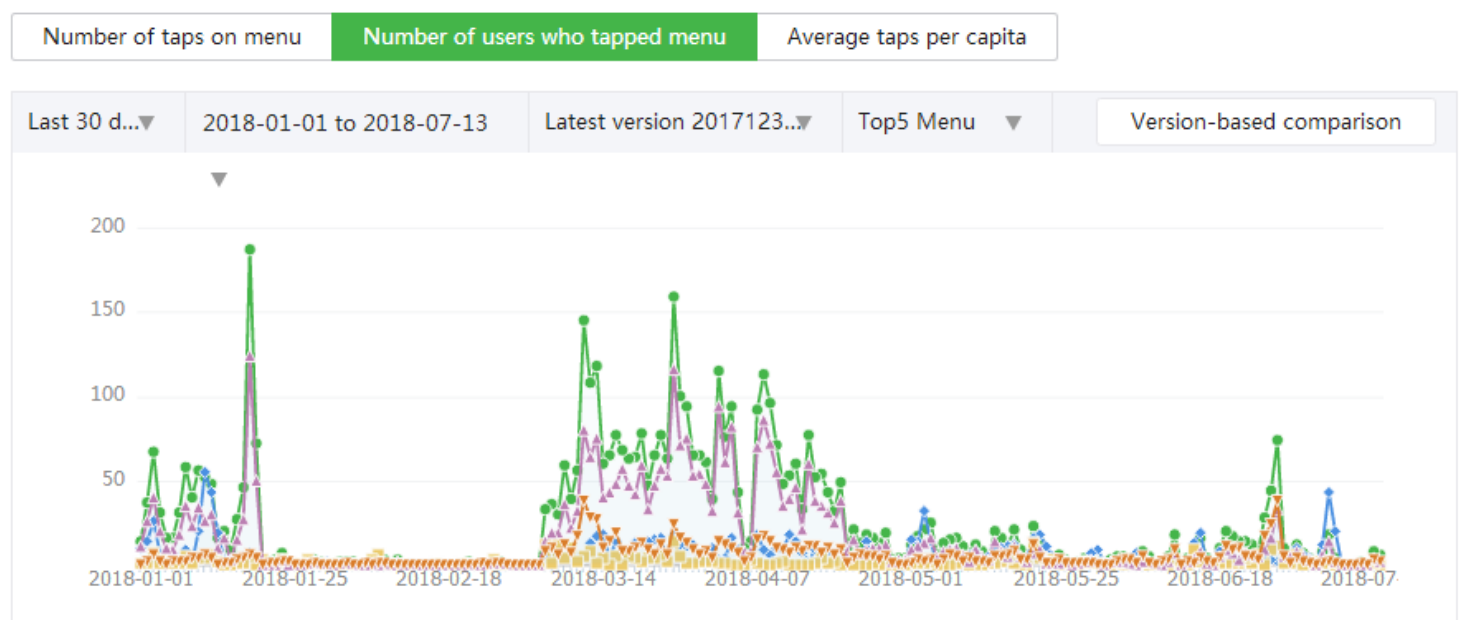

Fig. 4. The statistical data of students' autonomous learning 


\section{SUMMARY}

Application of teaching based on the Wechat public platform in mechanical drawing is quite successful and it has been extensively recognized and favored by students. According to the investigation results, over $82 \%$ of the students believe that Wechat public account exerts an active effect on learning. This pattern has motivated students' selflearning abilities, critical thinking abilities and innovative exploration abilities, greatly mobilized their interests of learning mechanical knowledge, facilitated further absorption, internalization and application of the knowledge and improved classroom learning efficiency. However, some problems still exist. Firstly, not only network techniques should be mastered but also mechanical knowledge-related professional contents and their extension should be explored and introduced; Secondly, the students have different requirements for the Wechat public platform. They can view the contents only through cellphones, so some students of weak self-control abilities will be indulged in playing cellphones; A minority of students making up a number without active work and just dealing with assignments indeed exists in mobile teaching of mechanical drawing course on the Wechat public platform, so how to reinforce supervision and guidance is still a problem needing urgent solutions.

\section{ACKNOWLEDGMENT}

The study was supported by the Project of Department of Education of Guangdong Province (Project Name: Research of Witkey-Based Teaching Pattern of Innovative and Entrepreneurial Practice for Mechanical Specialty), the Project of Education of Dongguan University of Technology (Project Name: Mechanical Drawing Teaching Team), the Project of Education of Dongguan University of Technology (Project Name: Reform and Improvement of Teaching Quality of Mechanical Basic Courses Based on the Cultivation of Innovative Talents), the Dongguan Social Science and Technology Development Project (NO.2013108101011, NO.2017507140058, NO.2017507140059), Dongguan Industrial Science and Technology Development Project (NO.2015222119), and the industrial-academic-research cooperation demonstration base of DGUT \& Hengli mold specialized town.

\section{REFERENCES}

[1] He-tiao HONG,Jie ZHOU. Design of Laboratory Equipment Management System Based on WeChat Public Platform. 2016 2nd International Conference on Humanity and Social Science (ICHSS 2016)299-304

[2] Shaofa Yang. Research on the Application of Wechat in College Ideological and Political Education, 2nd International Conference on Economics, Social Science, Arts, Education and Management Engineering (ESSAEME 2016) 376-379.

[3] J.W. Guo, X.C. Cao, H.Y. Huang, L. Xie, Z.Z. Sun, G.H. Wu, Witkeybased teaching pattern of innovative and entrepreneurial practice for mechanical specialty, 2nd International Conference on Electrical and Electronics: Techniques and Applications (2017) 237-239

[4] J.W. Guo, C. Xu, J.J. Jing, H.B. Chen, S. Wang, Application of virtual reality in engineering drawing teaching.WIT Transactions on Engineering Sciences, 97(2014) 1461-1466. 